\title{
La internación domiciliaria fue segura y efectiva para el cuidado de pacientes con enfermedades agudas
}

\author{
Hospital in the home: a randomised controlled trial. \\ Caplan G, Ward J, Brennan N, et al. MJA 170:156-160; 1999
}

\section{Objetivo}

Determinar si la internación domiciliaria (ID) es comparable a la hospitalaria en cuanto a seguridad, eficacia y satisfacción de pacientes y cuidadores.

\section{Diseño}

Ensayo clínico aleatorizado, estratificado* por procedencia del paciente (geriátrico vs. domicilio).

\section{Lugar}

Un hospital de referencia (terciario) afiliado a la Universidad de New South Wales, Gran Bretaña.

\section{Pacientes}

Pacientes ancianos con criterios de admisión hospitalaria que no tengan evidencia de shock, sin requerimientos de oxígeno, con cuidador disponible, que no vivieran fuera del área local del hospital y que no estuvieran "demasiado graves" a criterio del equipo tratante. Los pacientes que ingresaban al sistema de ID debían pasar a sus domicilios dentro de las 24 hs. de hecho el diagnóstico.

\section{Intervención}

Los pacientes fueron tratados en sus residencias habituales de acuerdo a los diagnósticos pertinentes, por un equipo domiciliario constituido por enfermeras, médicos del hospital y médicos de cabecera de cada paciente, fisioterapeutas y terapistas ocupacionales. Los pacientes del grupo control fueron tratados en forma con- vencional dentro del hospital sin participación de los médicos del estudio.

\section{Medición de resultados principales}

Se comparó el número de complicaciones en cada grupo (se buscaron en las historias clínicas referencias a los síndromes geriátricos más comunes) y se utilizó un método validado para cuantificar los efectos adversos (QAHCS). Se evaluó la satisfacción de los pacientes cuidadores y médicos de cabecera a través de una encuesta simple.

\section{Resultados principales}

Cien pacientes con diagnósticos de neumonía, infección urinaria, celulitis, endocarditis, osteomielitis, trombosis venosa profunda y accidentes cerebrovasculares ingresaron al estudio, siendo ambos grupos (ID y control) comparables al inicio. La incidencia de efectos adversos o muerte (punto final combinado*) fue similar entre los pacientes hospitalarios y los de ID (16.3\% y $11.8 \%)$, aunque fue estadísticamente menor la incidencia de confusión, complicaciones urinarias e intestinales. La satisfacción de pacientes y cuidadores fue superior en el grupo ID para los pacientes y similar para los médicos de cabecera. No hubo diferencias en el número de reinternaciones dentro de los 28 días del alta.

\section{Conclusiones}

La internación domiciliaria es segura en cuanto a complicaciones, comparada con la hospitalaria; y muestra mejor satisfacción dentro de los usuarios del sistema.

\section{COMENTARIO}

Hospital en el domicilio, internación domiciliaria, atención domiciliaria y otros tantos, son nombres cada vez más frecuentes en la bibliografía médica. Todos ellos hacen referencia a modalidades de atención médica que, si bien tienen el común denominador del domicilio, no siempre se refieren a formas comparables de atención. Algunos llaman con estos nombres al cuidado de pacientes crónicos, otros al de pacientes con patologías agudas; algunos refieren así a la atención médica, otros a prestaciones de enfermería o kinesiologia.

El cuidado de pacientes en sus domicilios es tan antiguo como la medicina misma. Sin embargo la idea de que el paciente puede estar en "su cama" cuando padece una enfermedad se ha recuperado en las últimas décadas. Los argumentos para tal resurgimiento van desde el posible menor número de complicaciones que en el medio hospitalario, hasta el menor costo de cada internación. Estos argumentos, si bien plausibles, carecen aún de suficiente evidencia bibliográfica.

Este estudio, con un diseño sólido como es el estudio aleatorizado, muestra que los resultados de las internaciones en pacientes que son cuidados en el domicilio no parecen ser peores, y hasta podrían ser mejores que las de pacientes homologables que son tratados dentro de los hospitales. Cabe aclarar que esto es válido para determinados pacientes preseleccionados por el estudio.

Este estudio incluye pacientes con patologías variadas (a diferencia de otras publicaciones recientes que se centran solo en determina- dos pacientes como enfermedad pulmonar obstructiva crónica o reemplazo de cadera). Esta elección de los autores aumenta la validez externa* del estudio ya que permite extender las conclusiones a un grupo amplio de pacientes que pueden beneficiarse con internaciones en sus casas. Pero el número total de paciente incluidos en este ensayo fue escaso. Por otro lado tiene como criterio de exclusión el hecho de que el paciente luzca "demasiado grave". Esto es una selección de pacientes pero por ser previa a la aleatorización es válida; con el mensaje de que la ID no es para cualquier paciente sino para aquellos que reúnen determinados criterios.

En nuestra experiencia la ID es factible y comparable a la internación hospitalaria.1 Para gran parte de las enfermedades clínicas que hoy en día ocupan camas de los hospitales, esta modalidad de atención puede ser beneficiosa; $y$ considerando que es una estrategia menos costosa, es probable que pronto alcance a gran parte de la población de pacientes internados.

Algunos requisitos van a ser indispensables: familias continentes y predispuestas a ser partícipes activas del cuidado del paciente y médicos con un poco de "audacia" para salir de las contenedoras cuatro paredes del hospital. Probablemente ningún paciente será despertado para tener el control de presión arterial de las dos de la mañana, ni comerá con tan poca sal como en el hospital; pero las conductas médicas se volverán más cercanas a las realidades socioeconómicas y sanitarias de los pacientes.

*Ver Glosario

\section{Dr. Juan Pablo Roubicek}

Medicina Interna. Mar del Plata. 